\title{
De-stiffening drug therapy and blood pressure control
}

\author{
This article was published in the following Dove Press journal: \\ Integrated Blood Pressure Control \\ 28 December 2009 \\ Number of times this article has been viewed
}

\author{
Michel E Safar \\ Paris-Descartes University, Faculty of \\ Medicine, Hôtel-Dieu Hospital, AP-HP, \\ Diagnosis Center, Paris, France
}

\begin{abstract}
In hypertensive subjects, cardiovascular risk reduction is critically related to the decrease of systolic blood pressure (SBP). De-stiffening therapy means that, in a controlled therapeutic trial of long duration, a selective reduction of SBP has been obtained in the studied group by comparison with the control group, and that this SBP reduction is due to a decrease of either arterial stiffness, or wave reflections, or both. Central SBP reduction and cardiovascular remodeling are specifically involved. Most protocols require the presence of an angiotensin II blocker, potentially associated with a diuretic compound and/or a calcium-channel blocker. Cardiovascular outcomes are significantly reduced by comparison with the control group, particularly when this latter group involves administration of a betablocking agent.
\end{abstract}

Keywords: hypertension, pulse pressure, large arteries, de-stiffening drug therapy

\section{Introduction}

A reduction in SBP has explained most of the treatment benefit in outcome trials in patients with hypertension. ${ }^{1-6}$ This benefit has been obtained mostly using ANG-II inhibition. Such findings focused attention on the factors that modulate SBP and PP levels in hypertensive individuals, and therefore on the role of increased arterial stiffness and/or wave reflections in the mechanism of hypertension.

This review has four parts: 1) Mechanisms of propagation of the pressure wave along the vascular circuit; 2) Pulsatile arterial hemodynamics as independent predictors of CV risk; 3) Relationship between pulsatile arterial hemodynamics and reninangiotensin system; and 4) Principal strategies for lowering large artery stiffness in the treatment of hypertension and CV prevention.

\section{Mechanisms of pressure wave propagation along the vascular tree}

There are two components of pressure and flow: a steady component and a pulsatile component. The former is represented by MAP, the product of blood flow by vascular resistance, an index of the "caliber" of small arteries. The latter is represented by PP, which is determined by stroke volume, arterial stiffness and wave reflections. The second two factors, but not stroke volume, are influenced by the ability to change the cyclic flow coming from the heart into a continuous flow at the peripheral level in order to obtain an adequate oxygenation of tissue.
Correspondence: Michel E Safar

Centre de Diagnostic et de

Thérapeutique, Hôtel-Dieu,

I place du Parvis Notre-Dame,

75181 Paris Cedex 04, France

$\mathrm{Tel}+33(0) \mid 42348025$

Fax +33 (0) I 42348632

Email michel.safar@htd.aphp.fr 


\section{Blood pressure propagation, arterial stiffness and wave reflections}

Following ventricular contraction, the pressure pulse generated by the heart travels along the aorta as a wave (Figure 1). It is possible to calculate the velocity of propagation of this wave (ie, PWV) along the aorta from the interval between two BP curves located at two different sites in the arterial tree (Figure 1). Because of the fundamental principle is that pulse waves travel faster in stiffer arteries, PWV measurement is considered the best surrogate to evaluate arterial stiffness. Its value is 3 to $5 \mathrm{~m} / \mathrm{s}$ in young persons at rest, but increases considerably with age (Figure 1). Given that peripheral arteries are markedly stiffer than central arteries, an important feature of PWV determinations is the large heterogeneity of the arterial tree.

When BP measurements are made simultaneously at different points along the aorta, the pressure wave changes shape as it travels down the aorta (Figure 2). Whereas SBP actually rises with distance from the heart, the DBP and MAP fall slightly (about $4 \mathrm{~mm} \mathrm{Hg}$ ) during the same course along the aortic trajectory. Thus, pressure-oscillation amplitude between systole and diastole, which is represented by PP (Figure 3) nearly doubles. This SBP and PP amplification (Figure 2) is a physiological finding, approximately $14 \mathrm{~mm} \mathrm{Hg}$ between the thoracic aorta root and the brachial artery, and continuing in aortic ramifications out to about the third-generation level of branches. Thereafter, both PP and
MAP drop sharply to the levels found in the microcirculation, a vascular area in which steady flow is nearly achieved.

If an individual's body length is about $2 \mathrm{~m}$ at most, and aortic PWV is approximately $5 \mathrm{~m} / \mathrm{s}$, something must happen to the shape of the BP curve within each beat if heart rate is $60 / \mathrm{min}$, which is the generation of wave reflections and their summation with the incident wave, as summarized in Figure 2. The incident wave is driven away from the heart through the highly conductive arteries. However, it encounters an impedance mismatch at the junction of the highly conductive artery and highly resistant arterioles, blocking its entry into the arterioles, and it is reflected, traveling backwards towards the heart (Figure 2). Thus, the shape of every pulse wave results from the summation of the incident (forward-traveling) and reflected (backward-traveling) pressure waves (Figure 3).

\section{Role of age on BP curve and wave reflections}

Reflected waves may be initiated from any discontinuity of the arterial or arteriolar wall, but are mainly issued from high resistance vessels. ${ }^{1,2}$ Pulse-wave propagation and reflection vary considerably according to age. In young adults at their maximum height and maximum elasticity of their central arteries (low PWV), the summation of the incident arterial pressure wave and the reflected wave results in progressive

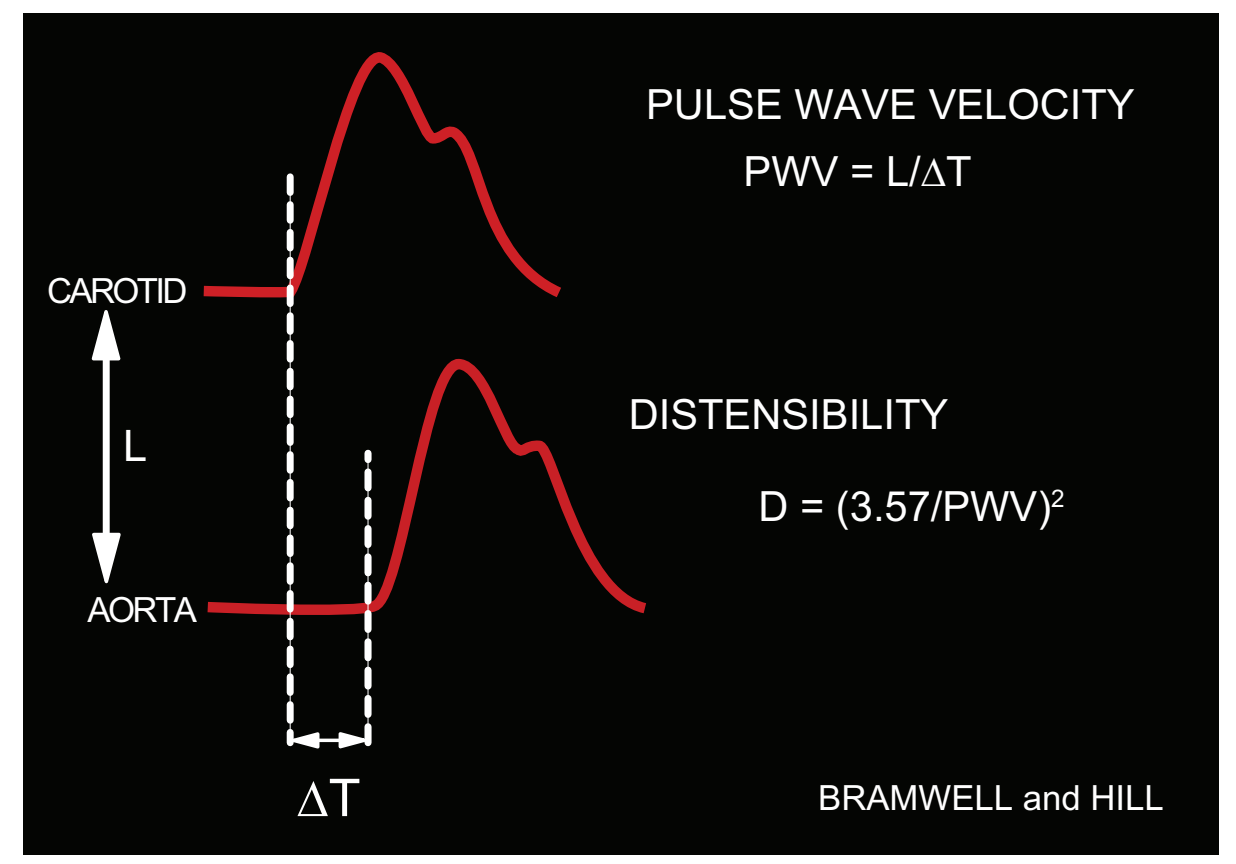

Figure I Clinical determination of PWV.PWV is the ratio between: I) the distance between the carotid and femoral transducers (L), and 2) the time delay ( $\Delta \mathrm{T})$ between the foot of the carotid and femoral BP curves simultaneously measured. From PWV, distensibility may be deduced. ${ }^{1,2}$ 


\section{Wave traveling}

\section{(1) Propagation (PWV)}
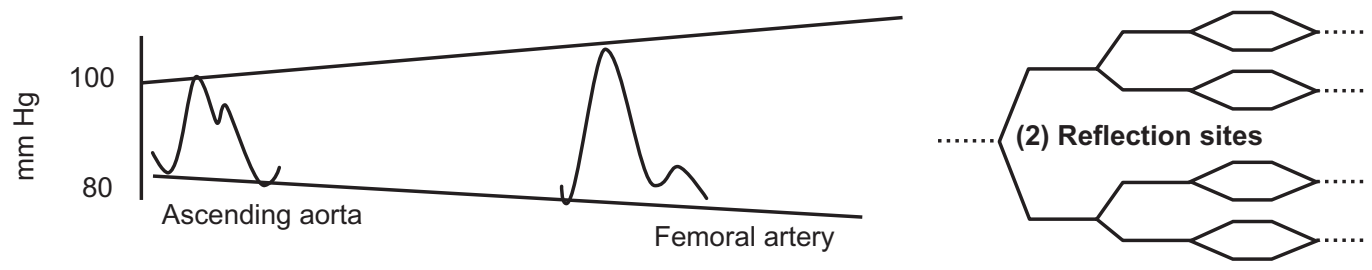

(3) Reflected wave

(Summation of incident

and reflected waves)

Figure 2 Progression of the pressure wave along the aortic tree. Three steps are involved: propagation, reflection, and summation of the incident and the reflected waves.

PP amplification, so that SBP is higher in the brachial artery than the ascending aorta (Figure 3). This hemodynamic profile contrasts with MAP and DBP, which decline minimally in vessels at increasing distance from the heart at all ages (Figure 2). Note that, in the thoracic aorta, because PWV is relatively low, the reflected wave comes back during diastole, thereby maintaining DBP and boosting coronary perfusion (Figure 3, lower part). Hence, an optimal arterial function is maintained, along with adequate coronary perfusion.
The pattern of wave reflections and the pulse wave shape are directly dependent on aging and arterial stiffness. The development of increasing arterial stiffness (high PWV) and altered wave reflections with aging and hypertension completely abolishes the differences between central and peripheral PP by age 50 to 60 years, with major consequences for ventricular load and coronary perfusion. The increased PWV means that the reflected waves return to the aortic root earlier, during late systole. In this situation, the reflected

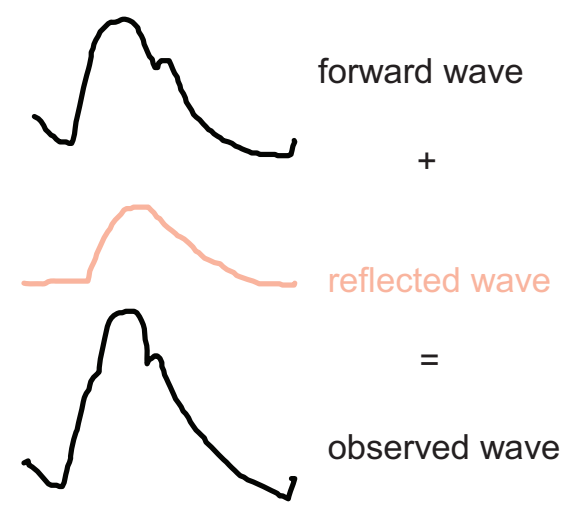

\section{Central PP}

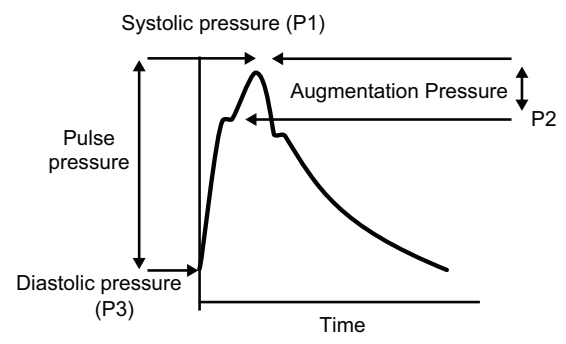

Alx = augmentation pressure/pulse pressure

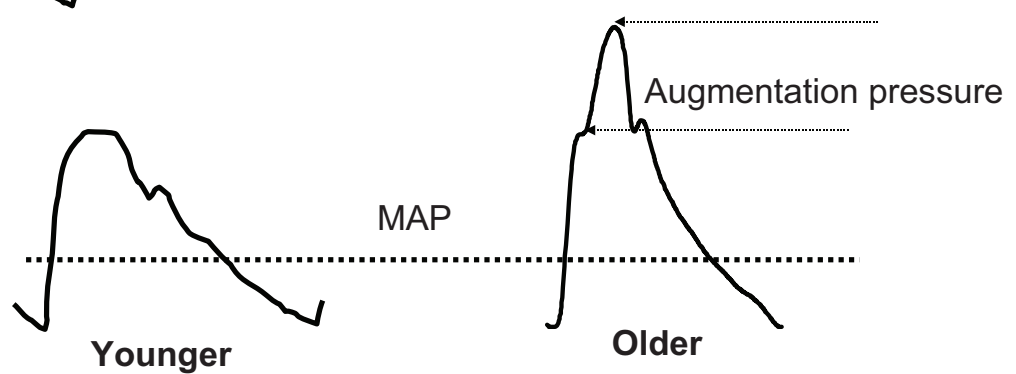

Figure 3 The upper part gives a schematic representation of the BP curve on the right, and the forward and reflected wave on the left. In the lower part, the BP curve is represented in younger (on the left) and in older (on the right) subjects. Augmentation index (Alx) is the ratio between: I) the difference between peak SBP and the shoulder of the ascending part of the BP curve, and 2) pulse pressure. Alx, measured in \%, represents the supplementary increase in SBP due to wave reflections. This hemodynamic profile is observed in the elderly, not in young people. MAP is mean arterial pressure, corresponding to the steady pressure necessary to a continuous cardiac pump. 
waves combine with the forward-traveling wave to create an increased "augmentation" of the central SBP and ventricular load (Figure 3, lower part). In elderly persons with isolated systolic hypertension, aortic SBP can be elevated by a much as 30 to $40 \mathrm{~mm} \mathrm{Hg}$ as a result of the early return of the wave reflection. ${ }^{1,2}$ Furthermore, because the backward pressure returns in systole, and not in diastole, as a consequence of enhanced PWV, DBP and coronary blood flow tend to be reduced, a situation favoring coronary ischemia. Finally, the classical phenotype of systolic hypertension in the elderly is observed (Figure 3). It is worth noting that reduced heart rate shifts wave reflection from diastole in systole, thus increasing central SBP. Inversely, angiotensin and calcium blockade as well as insulin reduce wave reflection and central SBP. Insulin resistance has an opposite effect.

\section{Mechanical forces and vascular remodeling}

It is important to note that an arterial wall is a complex tissue composed of different cell populations capable of structural and functional changes, in response to direct injury and atherogenic factors, or to modifications of long-term hemodynamic conditions. The principal geometric modifications induced by hemodynamic alterations are changes of the arterial lumen and/or arterial wall thickness due to activation, proliferation and migration of VSM cells, and rearrangements of cellular elements and ECM..$^{1,3-8}$ Chronic alterations of mechanical forces lead to modifications of the geometry and composition of the vessel walls, as observed in hypertension, particularly in the elderly. ${ }^{1,2,7}$ To maintain tensile stress within physiological limits, arteries respond by thickening their walls (Laplace's law). On the other hand experimental and clinical data indicate that acute and chronic augmentations of arterial blood flow induce proportional increases of the vessel lumen, whereas diminished flow leads to reduction of the inner arterial diameter. ${ }^{1,2,9}$ The presence of the endothelium is a major prerequisite for normal vascular adaptation to chronic changes of blood flow and pressure.

Hypertensive remodeling is characterized by the increased wall/lumen ratio of arterioles, which represent the site of vascular resistance and also the origin of wave reflections (Figure 1). ${ }^{9-12}$ Regression of arteriolar hypertrophy is associated with diminution of vascular resistance and of reflection coefficients, thereby causing a lower SBP, PP and AIx, a classical marker of wave reflections (Figure 3, lower side). ${ }^{10-12}$ This process occurs approximately after 1-year of treatment in hypertensive subjects under angiotensin or calcium blockade, but not under thiazide diuretics and/or beta-blocking agents. ${ }^{11}$
Endothelial dysfunction may sometimes participate to this process, mainly through NO deficiency and development of oxidative stress. ${ }^{1,2,9-13}$

\section{Pulsatile arterial hemodynamics as independent predictors of $\mathrm{CV}$ risk}

This section will show how brachial PP, aortic PWV, and to a greater extent central PP and wave reflections, are independent predictors of $\mathrm{CV}$ risk, implicating the possibility of specific drug treatments, called de-stiffening therapy, in relation with pulsatile arterial hemodynamics.

\section{Brachial PP}

Following the seminal works by Darné et al and Madhavan et al, ${ }^{14,15}$ several authors showed almost simultaneously ${ }^{16-18}$ that, after 50 to 60 years of age, brachial PP was a strong CV risk factor for myocardial infarction in populations of hypertensive individuals. The best predictor function of all possible linear combinations of SBP and DBP was shown to be similar to that of PP, indicating that their association was not a statistical artefact caused by the correlation between SBP and PP. ${ }^{18}$ The result was independent of MAP and stronger than for SBP. As shown in Figure 4, CV risk rises sharply with SBP. However, at any given SBP value, $\mathrm{CV}$ risk is higher when DBP is lower, ie, when PP is increased. ${ }^{17}$ This important finding was confirmed by the result of a longitudinal study ${ }^{19}$ which indicated that, during a 20 years follow-up, subjects with higher CV mortality were those whose SBP rose and DBP declined, and their CV mortality rate was significantly higher than that for those individuals whose SBP and DBP increased. ${ }^{19}$ Finally, it was demonstrated that, in the elderly, neither SBP nor DBP was superior to PP for predicting coronary risk and $\mathrm{PP}$ was found to be an independent predictor of CV mortality, even under drug treatment of hypertension. ${ }^{20,21}$ Similar results were obtained for individuals with recurrent myocardial infarction, congestive heart failure or myocardial dysfunction. Finally, brachial PP was shown to be predictor of CV risk in subjects with ESRD, diabetes mellitus or even systemic vasculitis. ${ }^{22-25}$

\section{Aortic PWV}

More recently, aortic PWV, a classic index of arterial stiffness, was shown to be an independent predictor of $\mathrm{CV}$ mortality in hypertensive individuals.

Based on the characteristics of patients ${ }^{26}$ with ESRD, logistic-regression and Cox analyses identified for the first time that the odds ratios for PWV $(>12 \mathrm{~m} / \mathrm{s})$ were $5.6(95 \%$ CI 2.4 to 11.9 for all-cause mortality, and 5.9 (95\% CI 2.3 to 15.5 ) for $\mathrm{CV}$ mortality. Furthermore, while the carotid 


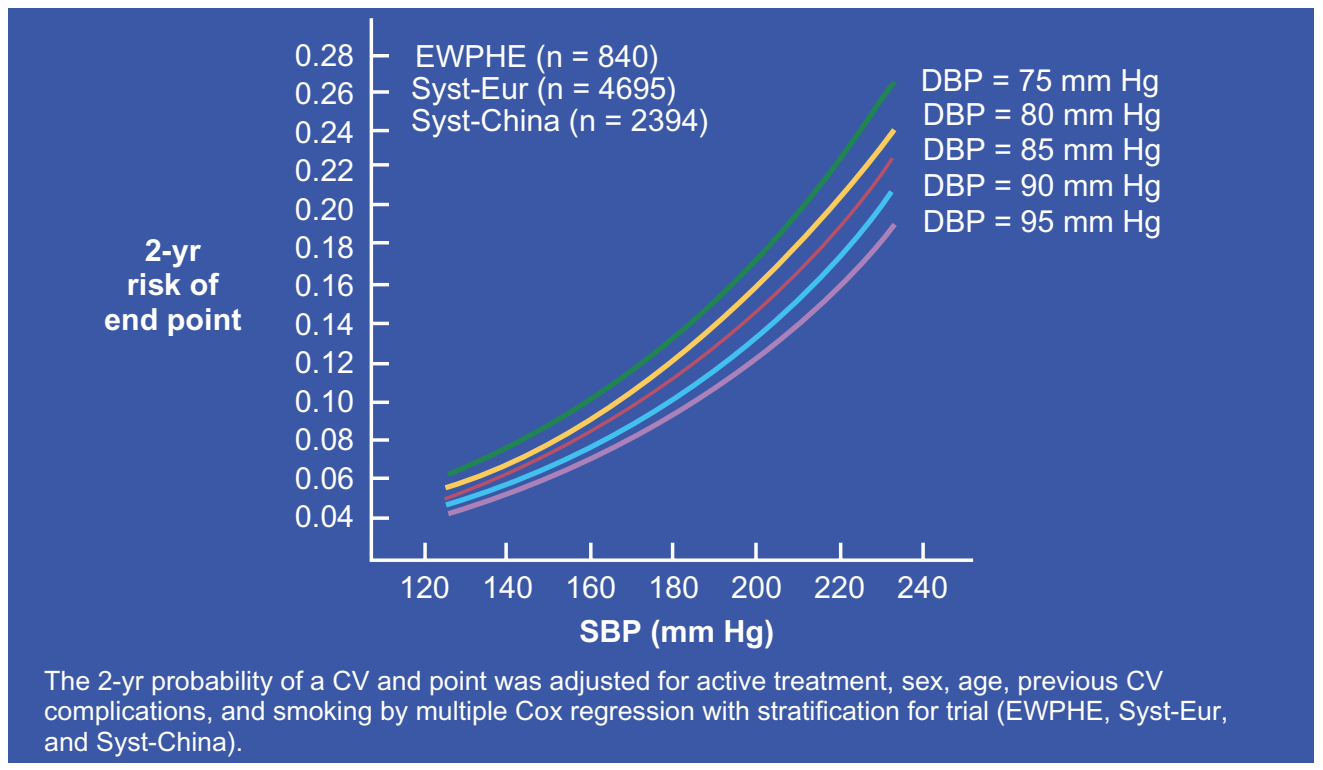

Figure 4 Curves plotting the 2-year risk of CV events in the elderly as a function of increasing SBP. Note that, at each given SBP value, the CV risk was higher when baseline DBP was lower. Reproduced with permission from Blacher J, Staessen JA, Girerd X, et al. Pulse pressure not mean pressure determines cardiovascular risk in older hypertensive patients. Arch Intern Med. 2000;160:1085-1089. ${ }^{17}$ Copyright (C) 2000 American Medical Association. All rights reserved.

wall/lumen ratio did not predict $\mathrm{CV}$ risk, carotid stiffness itself and carotid wave reflections (and not wall thickness) were a significant predictor of CV mortality. ${ }^{27,28}$ Similar observations were obtained for ESRD patients with diabetes mellitus ${ }^{29}$ and for kidney-transplant recipients. ${ }^{30}$

In subjects with essential hypertension, Blacher et $\mathrm{al}^{31}$ showed that $\mathrm{CV}$ risk assessed using Framingham equations was linearly associated with the PWV increase. Furthermore, the odds ratio of being at high risk of CV mortality ( $>5 \%$ for 10 years) for patients with PWV $>13.5 \mathrm{~m} / \mathrm{s}$ was $7.1(95 \%$ CI 4.5 to 11.3 ). That study ${ }^{32}$ provided the first evidence that a single aortic PWV measurement could be a strong independent predictor of CV risk for hypertensive patients. The results of longitudinal studies ${ }^{32-36}$ confirmed that aortic PWV is a significant and independent predictor of $\mathrm{CV}$ risk, more potent than PP itself.

\section{Central PP}

Studies of pulsatile arterial hemodynamics showed that, while MAP remains nearly constant along the arterial tree, PP rises markedly from central (thoracic aorta and carotid artery) to peripheral (brachial) arteries. This physiological amplification can be explained because the pressure-wave propagation along arterial vessels is associated with a progressive artery-diameter decline and arterial stiffness increase, resulting in modifications of wave-reflections (timing and/or amplitude). Therefore, aortic PP is expected to be more relevant to the investigation of $\mathrm{CV}$ risk than brachial PP, because it is closer to the heart, coronary arteries and carotid arteries, which are the most important sites of CV events. ${ }^{1,2}$ Aortic, but not brachial, pulsatility has been shown to be independently associated with CAD in patients undergoing coronary angiography before or after angioplasty. ${ }^{32,37,38}$ Furthermore, in 409 subjects followed for 4 to 5 years by Jankowski et al, ${ }^{39}$ a $10-\mathrm{mm} \mathrm{Hg}$ aortic PP increase was associated with a corresponding 13\% increase of $\mathrm{CV}$ events. In atherosclerotic subjects, central wave reflections were shown to be independent predictors of CAD. ${ }^{39}$ In ESRD patients, aortic PWV and carotid wave reflections (and/or central PP) were shown to predict independently CV mortality. ${ }^{1,2,40}$ Finally, in the same ESRD patients and in elderly subjects with essential hypertension, central PP was demonstrated to be an independent predictor of mortality. ${ }^{41}$ Taken together, all these findings suggest that central PP was superior to brachial PP for prediction of coronary risk and indicate that, during long-term antihypertensive drug therapy, serial central BP determinations are required to predict $\mathrm{CV}$ complications and justify the development of new de-stiffening strategies enabling to prevent $\mathrm{CV}$ risk. ${ }^{2}$

\section{Pulsatile arterial hemodynamics and renin-angiotensin system}

ANG-II blockade is classically associated with reduction of vascular resistance and MAP. In contrast, the effects on PWV 
and central and peripheral PP have been poorly investigated until recently. Studies on animal models and in humans suggest that ANG-II blockade is associated with reverse remodeling of both small and large arteries via specific mechanisms including anti-inflammatory and antifibrotic effects as well as changes of arterial attachments linking $\alpha 5 \beta 1$-integrin to its specific ligand fibronectin. ${ }^{42-44}$ Such effects are very important to consider in order tp obtain a significant and selective reduction of central PP and arterial stiffness under ANG-II blockade. They affect both small and large arteries and are acting through the MAP-kinase system. ${ }^{10,44}$

In hypertensive rats under low-salt diet (but not under high-salt diet), ANG-II blockade by the ARB valsartan normalizes central PP $(<50 \mathrm{~mm} \mathrm{Hg})$ but not MAP for the same drug dosage. ${ }^{42,43}$ In hypertensive subjects under ANGII blockade, not only PWV is decreased independently of MAP but also central wave reflections are attenuated and carotid-brachial SBP and PP amplification are increased. ANG-II blockade improves, or even normalizes, the wall thickness of small resistance arteries, and at the same time, reduces pressure wave reflections, suggesting a cause/effect relationship between the two factors. ${ }^{1,5}$ The arterial properties do not differ consistently whether ACEI or ARB are used and are the basis of all new strategies using de-stiffening therapy.
The Reason study ${ }^{10,45}$ was the first to investigate the long-term interactions among PP, arterial stiffness and wave reflections in relationship to drug treatment and end-organ damage (cardiac mass) in hypertensive subjects of the middle age. The ACEI Per, associated with low-dose Ind, was compared for 1 year of treatment with the beta-blocking agent atenolol. For the same DBP and MAP decreases, Per/Ind lowered SBP and PP more than atenolol (Figure 5). The reduction was more pronounced centrally (carotid artery) than peripherally (brachial artery). While the two drug regimens lowered PWV equally, only Per/Ind reduced central PP and AIx. ${ }^{10,45}$ In addition, Per/Ind decreased cardiac hypertrophy more than atenolol, and this diminution was attributed to the AIx decrease, indicating that the reduction of cardiac endorgan damage reflected mainly an effect on central wave reflections. ${ }^{10,45}$ Under drug treatment, the lowering of SBP was significantly predicted by baseline PWV.

\section{De-stiffening strategy and BP control ANG-II blockade and diuretics}

The main therapeutic trial demonstrating the predictive role of aortic stiffness in hypertensive subjects was conducted in ESRD patients on hemodialysis. ${ }^{46}$ The objective of that trial was to lower CV morbidity and mortality through a therapeutic regimen involving successively: salt and water depletion by

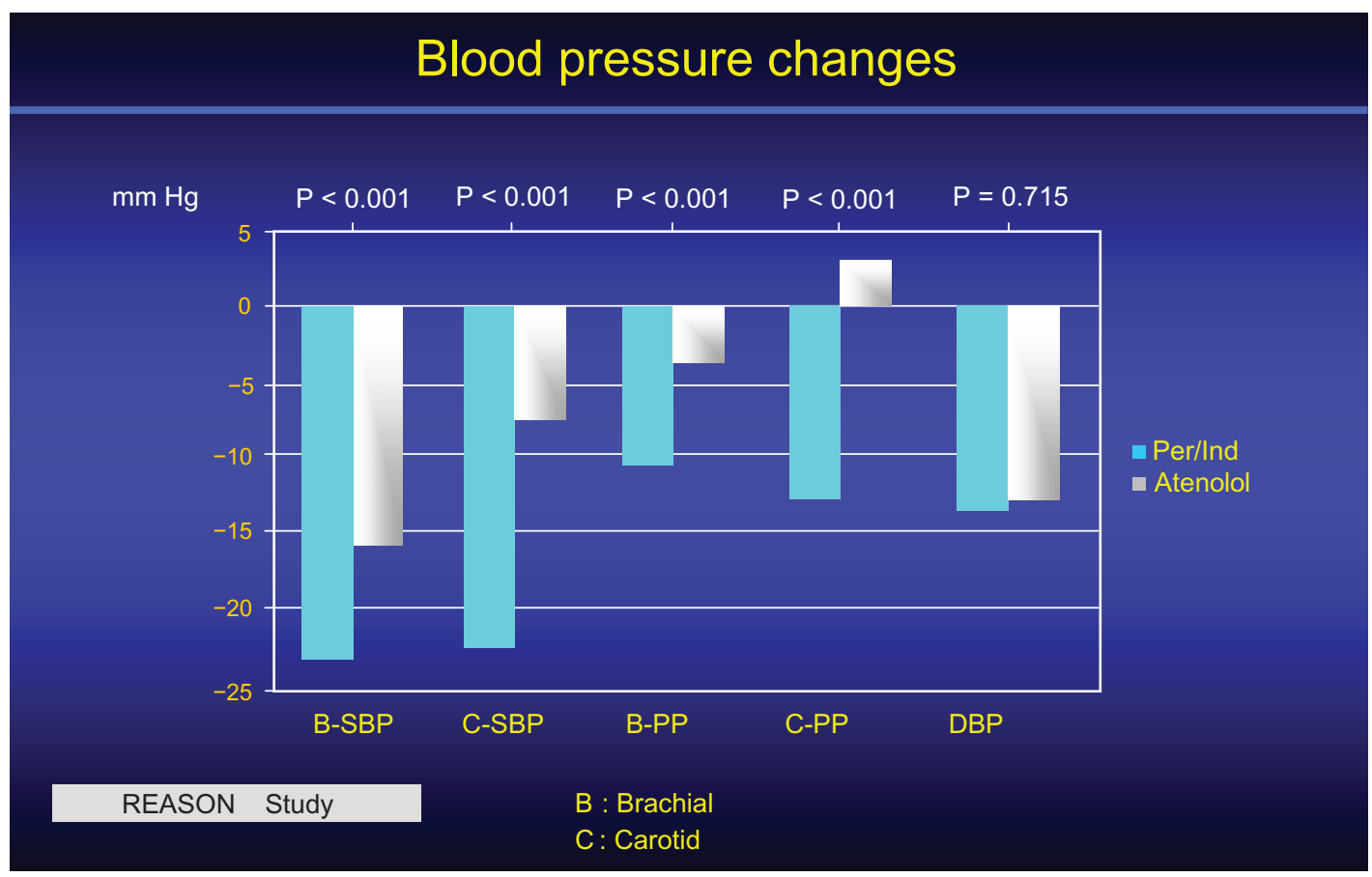

Figure 5 Central (C) and brachial (B) BP of the REASON study before and after one year treatment I0. Whereas the DBP reduction was similar for the 2 groups of subjects, the reduction of SBP and mostly of PP was more pronounced on central than brachial arteries, in favour of Per/Ind when compared to atenolol. Reproduced with permission from Asmar et al 2001. Hypertension. 2001;38:922-926. ${ }^{52}$ Copyright (C) 200I American Heart Association. 
dialysis; then, after randomization, ACEI or CCB; and, finally, the combination of the two agents and/or their association with a beta-blocker. Using that protocol, it was possible to evaluate, over long-term follow-up (51 months), whether or not the drug-induced MAP reduction was associated with a parallel diminution of PWV impacting on CV risk. During follow-up, it was evident that survivors' MAP, brachial PP and aortic PWV were lowered in parallel. In contrast, for patients who died from CV events, MAP had been reduced to the same extent as in survivors, but drug treatment had not significantly modified PWV or brachial PP. Thus, survival of ESRD patients was significantly better when aortic PWV declined in response to BP lowering. The adjusted relative risks for all-cause and $\mathrm{CV}$ mortality rates in those with unchanged $\mathrm{PWV}$ in response to BP changes were respectively: 2.59 (95\% CI, 1.51 to 4.43$)$ and 2.35 (95\% CI, 1.23 to 4.51$)(P<0.01)$. The prognosis value of PWV sensitivity to BP reduction on survival was independent of age, BP changes and blood-chemistry abnormalities (Figure 5). The results indicated that arterial stiffness was not only a risk factor contributing to the development of CV disease but also that it was a marker of established, more advanced and less reversible arterial lesions. This interpretation was supported by the loss of aortic PWV sensitivity to BP lowering for nonsurvivors, compared to survivors whose arterial stiffness remained responsive to BP reduction. Finally, in that trial, prolonged survival seemed to be more closely associated with the use of an ACEI than other drugs or the number of drugs per se. The use of beta-blockers and/or CCB had no direct impact on the outcomes. ${ }^{46}$

In diabetes subjects, the Per/Ind combination was studied in double-blind vs placebo with or without intensive glucose therapy. The BP control was followed for 4.3 years in 11,340 subjects. Reduction of BP was associated with a reduction of overall and $\mathrm{CV}$ mortality. The prediction of CV mortality was significant for brachial artery SBP and PP but not for MAP and DBP. It is worth noting that only diabetes mellitus, and not BP, was the criterion of selection of ADVANCE. ${ }^{47}$ However, the predictive values were in agreement with those of REASON. ${ }^{53}$

\section{ANG-II blockade and CCB blockade}

The CAFE study, a subanalysis of the ASCOT trial 48, conducted on 2073 subjects, showed that aortic PP, recorded noninvasively by radial tonometry and the application of generalized transfer functions, was a determinant of clinical outcomes, independently of age, other traditional CV risk factors and even peripheral PP. In agreement with the REASON study, ${ }^{10,45}$ the results of the CAFE study showed that treating subjects with a regimen based on the beta-blocker atenolol and a diuretic versus one based on the $\mathrm{CCB}$ amlodipine and an ACEI had similar effects on brachial SBP and PP but different effects on central aortic pressures. ${ }^{48}$ Even though brachial pressure reductions were similar for the two arms of the study, central SBP and PP decreases were greater for the CCB amlodipine and the ACEI Per arm. That study's results not only demonstrated that brachial PP does not always reflect the effect of different pressure-lowering treatments on central aortic pressures, but also suggested that central pressure changes might better predict clinical outcomes other than brachial pressures. ${ }^{48}$ Therefore, antihypertensive drug therapy should selectively lower SBP and PP through complex interactions between small and large artery effects, thereby opening the way for the development of new long-term CV-treatment strategies involving both small and large arteries.

The comparison effects between a CCB and a diuretic in combination with the same ARB OLM were studied using aortic SBP and brachial ambulatory SBP. ${ }^{49}$ This was a prospective, randomized, open-label, blinded end-point study in 207 hypertensive patients (mean age: 68.4 years). Patients received OLM monotherapy for 12 weeks, followed by additional use of AZE $(\mathrm{n}=103)$ or hydrochlorothiazide $(\mathrm{n}=104)$ for 24 weeks after randomization. After adjustment for baseline covariates, the extent of reduction in central SBP of the OLM/AZE group was significantly greater than that in the OLM/DIURETIC group (between-group difference 95\% CI 5.20 .3 to $10.2 \mathrm{~mm} \mathrm{Hg}$, $P=0.039$ ), while the difference in the reduction in brachial SBP between the groups was not significant (2.6 to 2.2 to $7.5 \mathrm{~mm} \mathrm{Hg}, P=0.29$. The aortic PWV showed a significantly greater reduction for the OLM/AZE combination than for the OLM/DIURETIC combination (08 0.5 to $1.1 \mathrm{~m} / \mathrm{s}, P<0.001$ ) after adjustment for covariates. The extent of reduction in brachial ambulatory SBP was similar between the groups. These data showed that the combination of OLM $20 \mathrm{mg} / \mathrm{AZE} 16 \mathrm{mg}$ had a more beneficial effect on central SBP and arterial stiffness than the combination of OLM $20 \mathrm{mg}$ /hydrochlorothiazide $12.5 \mathrm{mg}$, despite the lack of a significant difference in brachial SBP reduction between the two treatments.

In the present study, Matsui et $\mathrm{al}^{49}$ have provided evidence on the mechanism of reduction of SBP and PP amplification by $\mathrm{CCB}$, namely by reducing PWV and AIx. CCB is a powerful vasodilating agent, increasing the large artery diameter independently of BP reduction and of any endothelium-dependent effect. Reduction of pressure wave reflections is the second important mechanism of central SBP reduction by CCB. Although heart rate was decreased in the OLM/AZE arm, thus favoring an earlier timing of wave reflections in systole, AI was reduced. 
This may be explained partly by the prolonged time of return of the reflected wave, due to lower PWV. Another possibility is that the long-term drug treatment causes regression of arteriolar hypertrophy as usually observed under CCB treatment. This might cause distal shift of reflections sites or decrease of reflection coefficients, thus lowering amplitude of wave reflections. ${ }^{5}$ The same possibility may be observed with ANG-II blockade, but not with diuretic or traditional beta-blocking agents given alone. ${ }^{50}$ Whether AZE has such effects, most likely via arteriolar vasodilatation and structural changes, or by altering baroreflex sensitivity, or even acting synergistically with ANG-II blockade, ${ }^{51}$ are possibilities that merit further exploration.

In conclusion, this report has shown that it is possible to obtain in the long term a selective reduction of brachial and mostly central PP through a decrease of arterial stiffness and wave reflections. Most of the therapeutic protocols involve angiotensin blockade. Because $\mathrm{CV}$ reduction is dominantly related to the control of SBP, the de-stiffening strategy should be now extensively developed.

\section{Abbreviations}

ACEI, angiotensin-converting-enzyme inhibitor; AIx, augmentation index; AI, augmentation pressure; ANG-II, angiotensin II; ARB, angiotensin AT1-receptor blocker; AZE, azelnidipine; BP, blood pressure; CAD, coronary artery disease; $\mathrm{CCB}$, calcium channel blocker; CI, confidence interval; CV, cardiovascular; DBP, diastolic blood pressure; ECM, extracellular matrix; ESRD, end-stage renal disease; Ind, indapamide; MAP, mean arterial pressure; NO, nitrite oxide; OLM, olmesartan; Per, perindopril; PP, pulse pressure; PWV, pulse wave velocity; BP, systolic blood pressure; VSM, vascular smooth muscle.

\section{Acknowledgments}

This work was performed with the help of INSERM (Institut de la Santé et de la Recherche Médicale) and GPH-CV (Groupe de Pharmacologie et d'Hémodynamique Cardiovasculaire), Paris. We thank Dr Anne Safar for helpful and stimulating discussions.

\section{Disclosure}

The author declares no conflicts of interest.

\section{References}

1. Nichols WW, O'Rourke MF. McDonald's Blood Flow in Arteries. Theoretical, Experimental and Clinical Principles, 4th ed, Edward Arnold: London; 2006:49-94, 193-233, 339-402, 435-502.

2. Safar ME, O'Rourke MF. Arterial stiffness in hypertension. In: Handbook of Hypertension, Elsevier; 2006:3-62, 75-136, 459-501.
3. Black HR. The paradigm has shifted, to systolic blood pressure. Hypertension. 1999;34:386-387.

4. Kannel WB, Gordon T, Schwartz MJ. Systolic versus diastolic blood pressure and risk of coronary heart disease. The Framingham study. Am J Cardiol. 1971;27:335-346.

5. Kannel WB. Hypertension as a cardiovascular risk factor. In: Bulpitt CJ editor. Handbook of Hypertension. Epidemiology of Hypertension. Elsevier Science: Amsterdam; 1985. pp. 15-34.

6. Mancia G, Grassi G. Systolic and diastolic blood pressure control in antihypertensive drug trials. J Hypertens. 2002;20:1461-1464.

7. Langille BL. Remodeling of developing and mature arteries: endothelium, smooth muscle, and matrix. J Cardiovasc Pharmacol. 1993;21 Suppl 1: S11-S117.

8. Levy BI, Ambrosio G, Pries AR, Struijker-Boudier HA. Microcirculation in hypertension: a new target for treatment? Circulation. 2001;104:735-740.

9. Gibbons GH, Dzau VJ. The emerging concept of vascular remodeling. N Engl J Med. 1994;330:1431-1438.

10. London GM, Asmar RG, O'Rourke MF, Safar ME. And on behalf of the REASON project. Mechanism(s) of selective systolic blood pressure reduction after a low-dose combination of perindopril/indapamide in hypertensive subjects: comparison with atenolol. J Am Coll Cardiol. 2004;43:92-99.

11. Safar ME, Rizzoni D, Blacher J, Muiesan ML, Agabiti-Rosei E. Macro and microvasculature in hypertension: therapeutic aspects. $J$ Hum Hypertens. 2008;22:590-595.

12. Williams B. Mechanical influences on vascular smooth muscle cell function. J Hypertens. 1998;16:1921-1929.

13. Glagov S. Hemodynamic risk factors: mechanical stress, mural architecture, medial nutrition and vulnearbility of arteries to atherosclerosis. In: Wissler RW, Geer JC, Editors. The Pathogenesis of Atherosclerosis. Williams \& Wilkins: Baltimore; 1972. pp. 164-199.

14. Darné B, Girerd X, Safar M, Cambien F, Guize L. Pulsatile versus steady component of blood pressure: a cross-sectional analysis and a prospective analysis on cardiovascular mortality. Hypertension. 1989;13:392-400.

15. Madhavan S, Ooi WL, Cohen H, Alderman MH. Relation of pulse pressure and blood pressure reduction to the incidence of myocardial infarction. Hypertension. 1994;23:395-401.

16. Franklin SS, Khan SA, Wong ND, Larson MG, Levy D. Is pulse pressure useful in predicting risk for coronary heart Disease? The Framingham heart study. Circulation. 1999;100:354-360.

17. Blacher J, Staessen JA, Girerd X, et al. Pulse pressure not mean pressure determines cardiovascular risk in older hypertensive patients. Arch Intern Med. 2000;160:1085-1089.

18. Millar JA, Lever AF, Burke V. Pulse pressure as a risk factor for cardiovascular events in the MRC Mild Hypertension Trial. J Hypertens. 1999; 17:1065-1072.

19. Benetos A, Zureik M, Morcet J, et al. A decrease in diastolic blood pressure combined with an increase in systolic blood pressure is associated with a higher cardiovascular mortality in men. J Am Coll Cardiol. 2000;35:673-680.

20. Domanski MJ, Davis BR, Pfeffer MA, Kastantin M, Mitchell GF. Isolated systolic hypertension: prognostic information provided by pulse pressure. Hypertension. 1999;34:375-380.

21. Mitchell GF, Moye LA, Braunwald E, et al. Sphygmomanometrically determined pulse pressure is a powerful independent predictor of recurrent events after myocardial infarction in patients with impaired left ventricular function. SAVE investigators. Survival and Ventricular Enlargement. Circulation. 1997;96:4254-4260.

22. Chae CU, Pfeffer MA, Glynn RJ, Mitchell GF, Taylor JO, Hennekens $\mathrm{CH}$. Increased pulse pressure and risk of heart failure in the elderly. JAMA. 1999;281:634-639.

23. Klassen PS, Lowrie EG, Reddan DN, et al. Association between pulse pressure and mortality in patients undergoing maintenance hemodialysis. JAMA. 2002;287:1548-1555.

24. Schram MT, Kostense PJ, Van Dijk RA, et al. Diabetes, pulse pressure and cardiovascular mortality: the Hoorn Study. J Hypertens. 2002;20:1743-1751. 
25. Benetos A, Safar M, Rudnichi A, et al. Pulse pressure: a predictor of long-term cardiovascular mortality in a French male population. Hypertension. 1997;30:1410-1415.

26. Blacher J, Guerin AP, Pannier B, Marchais SJ, Safar ME, London GM. Impact of aortic stiffness on survival in end-stage renal disease. Circulation. 1999;99:2434-2439.

27. Blacher J, Pannier B, Guerin AP, Marchais SJ, Safar ME, London GM. Carotid arterial stiffness as a predictor of cardiovascular and all-cause mortality in end-stage renal disease. Hypertension. 1998;32:570-574.

28. London GM, Blacher J, Pannier B, Guerin AP, Marchais SJ, Safar ME Arterial wave reflections and survival in end-stage renal failure. Hypertension. 2001;38:434-438.

29. Shoji T, Emoto M, Shinohara K, et al. Diabetes mellitus, aortic stiffness, and cardiovascular mortality in end-stage renal disease. J Am Soc Nephrol. 2001;12:2117-2124.

30. Barenbrock M, Kosch M, Joster E, Kisters K, Rahn KH, Hausberg M. Reduced arterial distensibility is a predictor of cardiovascular disease in patients after renal transplantation. J Hypertens. 2002;20:79-84.

31. Blacher J, Asmar R, Djane S, London GM, Safar ME. Aortic pulse wave velocity as a marker of cardiovascular risk in hypertensive patients. Hypertension. 1999;33:1111-1117.

32. Stefanadis C, Wooley CF, Bush CA, Kolibash AJ, Boudoulas H. Aortic distensibility abnormalities in coronary artery disease. Am J Cardiol. 1987;59:1300-1304.

33. Laurent S, Boutouyrie P, Asmar R, et al. Aortic stiffness is an independent predictor of all-cause and cardiovascular mortality in hypertensive patients. Hypertension. 2001;37:1236-1241.

34. Meaume S, Benetos A, Henry OF, Rudnichi A, Safar ME. Aortic pulse wave velocity predicts cardiovascular mortality in subjects $>70$ years of age. Arterioscler Thromb Vasc Biol. 2001;21:2046-2050.

35. Willum-Hansen T, Staessen JA, Torp-Pedersen C, et al. Prognostic value of aortic pulse wave velocity as index of arterial stiffness in the general population. Circulation. 2006;113:664-670.

36. Cruickshank K, Riste L, Anderson SG, Wright JS, Dunn G, Gosling RG. Aortic pulse-wave velocity and its relationship to mortality in diabetes and glucose intolerance: an integrated index of vascular function? Circulation. 2002;106:2085-2090.

37. Hirai T, Sasayama S, Kawasaki T, Yagi S. Stiffness of systemic arteries in patients with myocardial infarction. A noninvasive method to predict severity of coronary atherosclerosis. Circulation. 1989;80:78-86.

38. Gatzka CD, Cameron JD, Kingwell BA, Dart AM. Relation between coronary artery disease, aortic stiffness, and left ventricular structure in a population sample. Hypertension. 1998;32:575-578.

39. Jankowski P, Kawecka-Jaszcz K, Czarnecka D, et al. Pulsatile but not steady component of blood pressure predicts cardiovascular events in coronary patients. Hypertension. 2008;51:848-855.
40. Weber T, Auer J, O'Rourke MF, et al. Arterial stiffness, wave reflections, and the risk of coronary artery disease. Circulation. 2004;109:184-189.

41. Safar ME, Blacher J, Pannier B, et al. Central pulse pressure and mortality in end-stage renal disease. Hypertension. 2002;39:735-738.

42. Kakou A, Bezie Y, Mercier N, et al. Selective reduction of central pulse pressure under angiotensin blockage in SHR: role of the fibronectinalpha5beta1 integrin complex. Am J Hypertens. 2009;22:711-717.

43. Labat C, Lacolley P, Lajemi M, de Gasparo M, Safar ME, Benetos A. Effects of valsartan on mechanical properties of the carotid artery in spontaneously hypertensive rats under high-salt diet. Hypertension. 2001;38:439-443.

44. Louis H, Kakou A, Regnault V, et al. Role of alphalbeta1-integrin in arterial stiffness and angiotensin-induced arterial wall hypertrophy in mice. Am J Physiol Heart Circ Physiol. 2007;293:H2597-H2604.

45. de Luca N, Asmar RG, London GM, O’Rourke MF, Safar ME. Selective reduction of cardiac mass and central blood pressure on low-dose combination perindopril/indapamide in hypertensive subjects. J Hypertens. 2004;22:1623-1630.

46. Guerin AP, Blacher J, Pannier B, Marchais SJ, Safar ME, London GM. Impact of aortic stiffness attenuation on survival of patients in end-stage renal failure. Circulation. 2001;103:987-992.

47. Kengne AP, Czernichow S, Huxley R, et al. Blood pressure variables and cardiovascular risk: new findings from ADVANCE. Hypertension. 2009;54:399-404.

48. Williams B, Lacy PS, Thom SM, et al. Differential impact of blood pressure-lowering drugs on central aortic pressure and clinical outcomes: principal results of the Conduit Artery Function Evaluation (CAFE) study. Circulation. 2006;113:1213-1225.

49. Matsui Y, Eguchi K, O’Rourke MF, et al. Differential effects between a calcium channel blocker and a diuretic when used in combination with angiotensin ii receptor blocker on central aortic pressure in hypertensive patients. Hypertension. 2009;54:716-723.

50. Agabiti-Rosei E, Heagerty AM, Rizzoni D. Effects of antihypertensive treatment on small artery remodelling. J Hypertens. 2009;27: 1107-1114.

51. Jinno T, Iwai M, Li Z, et al. Calcium channel blocker azelnidipine enhances vascular protective effects of AT1 receptor blocker olmesartan. Hypertension. 2004;43:263-269.

52. Asmar RG, London GM, O’Rourke ME, Safar ME; REASON Project Coordinators and Investigators. Improvement in blood pressure, arterial stiffness and wave reflections with a very-low-dose perindopril/ indapamide combination in hypertensive patient: a comparison with atenolol. Hypertension. 2001;38:922-926.

53. ADVANCE Collaborative Group, Patel A, MacMahon S, Chalmers J, et al. Intensive blood glucose control and vascular outcomes in patients with type 2 diabetes. N Engl J Med. 2008;358:2560-2572.
Integrated Blood Pressure Control

\section{Publish your work in this journal}

Integrated Blood Pressure Control is an international, peer-reviewed open-access journal focusing on the integrated approach to managing hypertension and risk reduction. Treating the patient and comorbidities together with diet and lifestyle modification and optimizing healthcare resources through a multidisciplinary team approach constitute key

\section{Dovepress}

features of the journal. This journal is indexed on American Chemical Society's Chemical Abstracts Service (CAS). The manuscript management system is completely online and includes a very quick and fair peerreview system, which is all easy to use. Visit http://www.dovepress.com/ testimonials.php to read real quotes from published authors. 